\title{
ANALISIS PERSEPSI STAKEHOLDER TERKAIT IMPLEMENTASI KAWASAN EKONOMI KHUSUS (KEK) VERSUS FREE TRADE ZONE (FTZ) DI KOTA BATAM
}

\author{
${ }^{1}$ Rikson Pandapotan Tampubolon \\ ${ }^{1}$ Universitas Putera Batam
}

rp_tpbolon@ymail.com

\begin{abstract}
This study aims to evaluate the free trade zone system that has been carried out with the planned implementation of special economic zones in Batam City. The economic downturn in the city of Batam has made stakeholders think again about the concept of free trade zone (ftz) or Free Port and Free Trade Zone. The FTZ concept is deemed no longer compatible with the current flow and competitiveness of change. For this reason, the central government offers the concept of special economic zones (KEK) to revive the passion of economic growth in this Industrial City. However, in the implementation there were many criticisms made by the community, especially businessmen who considered SEZ not to answer the problems that exist in Batam's economic growth. This study uses a qualitative approach to see each perception from stakeholders (stakeholders) to be a consideration in making decisions. Based on the results of the analysis, it was found that it was important that all stakeholders would sit together to discuss the good about the economy. The government must prioritize a bottom-up approach to find solutions to problems regarding the polemic of the best economic system problems for Batam City.
\end{abstract}

Keywords: Special Economic Zone, Free Trade Zone, Batam

\begin{abstract}
ABSTRAK
Penelitian ini bertujuan untuk mengevaluasi tentang sistem free trade zone yang sudah dilakukan dengan rencana penerapan kawasan ekonomi khusus di Kota Batam. Keterpurukan ekonomi kota batam membuat para pemangku kepentingan berpikir ulang tentang konsep free trade zone (ftz) atau Kawasan Perdagangan Bebas Dan Pelabuhan Bebas. Konsep FTZ dianggap tidak lagi kompatibel dengan arus dan daya saing perubahan sekarang ini. Untuk itu pemerintah pusat menawarkan konsep kawasan ekonomi khusus (KEK) untuk membangkitkan kembali gairah pertumbuhan ekonomi di Kota Industri ini. Namun dalam pelaksanaannya banyak kritik yang disampaikan masyarakat, khususnya kalangan pengusaha yang menganggap KEK tidak menjawab permasalahan yang ada dalam pertumbuhan ekonomi Batam. Penelitian ini menggunakan pendekatan kualitatif untuk melihat masing-masing persepsi dari stakeholder (pemangku kepentingan) untuk menjadi pertimbangan dalam mengambil keputusan. Berdasarkan hasil analisis diperoleh bahwa penting agar segenap pemangku kepentingan mau duduk bersama untuk membahas kebaikan tentang ekonomi batam. Pemerintah harus mengedepankan pendekatan bottom-up untuk mencari solusi permasalahan mengenai polemik permasalahan sistem ekonomi terbaik bagi Kota Batam.
\end{abstract}

Kata Kunci: kawasan ekonomi khusus, free trade zone, Batam

\section{PENDAHULUAN}

Kelesuan ekonomi Kota Batam, semakin tidak menarik ditambah wacana maju mundur mengenai sistem ekonomi di Kota Industri ini. Pemerintah dan pengusaha ribut mengenai usulan mengubah konsep FTZ (Free Trade Zone) menjadi KEK (Kawasan Ekonomi Khusus) yang ditawarkan oleh pemerintah. Sementara itu, masyarakat Kota Batam hidupnya semakin susah akibat ekonomi yang "kurang darah". Tak pelak, Batam yang dulu menjadi kota primadona tempat mengais rezeki, kini jadi ladang gersang bagi mereka para pencari kerja. Masihkah ada harapan?

Riuh rendah pro dan kontra mengenai transformasi ekonomi kota batam, sialnya berlangsung secara elitis. Pengusaha beranggapan sistem FTZ hari ini masih tetap kompatibel dengan ekonomi batam. Sementara itu pemerintah datang membawa konsep baru yaitu KEK, yang diklaim dapat memberikan kemudahan dan insentif ekonomi yang menggiurkan investor. Akibatnya, penguasa dan pengusaha silang pendapat mengenai sistem ekonomi yang terbaik 
digunakan di Batam. Lalu dimanakah posisi masyarakat kita?

Batam memiliki keunikan tersendiri karena ditetapkan sebagai kota kawasan perdagangan bebas dan pelabuhan bebas (Free Trade Zone). Keunikan tersebut semula dirancang untuk membangun gairah lebih, dalam membangun perekonomian daerah ini, sekaligus sebagai tulang punggung dan motor perekonomian nasional. Tidak bisa dipungkiri, letaknya yang sangat strategis berbatasan langsung dengan negara Singapura dan Malaysia - sebagai dua negara prospektif dan menjadi hub negara kawasan Asia Pasifik. Serta berada dalam jalur perdagangan tersibuk di dunia yaitu jalur Selat Malaka, membuat Batam begitu "seksi"dan diminati investor.

Terbukti, beberapa tahun sebelumnya tingkat pertumbuhan ekonomi Kota Batam selalu bertumbuh jauh melebihi pertumbuhan ekonomi nasional. Namun sialnya, belakangan ini tingkat ekonomi kota Batam merosot jauh meninggalkan pertumbuhan ekonomi nasional. Tahun 2017, ekonomi Batam hanya dapat mencatatkan tingkat pertumbuhan ekonomi sekitar dua persen, sedangkan pertumbuhan ekonomi nasional berada di 5,07 persen.

Kondisi perekonomian global yang lesu, turut andil dalam membuat perekonomian Kota Batam mengalami kemunduran. Harga minyak dunia yang jatuh dan geopolitik serta geoekonomi dunia, dituding sebagai sebab dari lesunya perekonomian global tersebut. Belum lagi kondisi internal Kota Batam sendiri masih banyak mengalami kendala dalam iklim investasinya, utamanya dalam hal perizinan, khususnya masalah lahan dalam dualisme kepemimpinan yang tumpang tindih di kota ini.

Kolaborasi faktor-faktor negatif diatas membuat kondisi Batam semakin terpuruk. Batam semakin terpuruk akibat perekonomian kota ini digantung pada sektor industri dan perdagangan yang sangat sensitif berpengaruh pada gejolak perekonomian global. Akibatnya, pemutusan kerja terjadi dimanamana. Banyak perusahaan yang gulung tikar. Perusahan galangan kapal yang sempat menjadi tulang punggung ekonomi Batam banyak yang tutup. Akibatnya, kemiskinan meningkat dan fenomena "pulang kampung"-karena tidak mampu bertahan hidup di Kota Batam - menjadi pemandangan yang jamak di kota ini.

\section{TINJAUAN PUSTAKA \\ Free Trade Zone Batam}

Menurut Wikipedia, Kawasan

Perdagangan Bebas Indonesia (bahasa Inggris: Indonesian Free Trade Zone) adalah sebuah kawasan perdagangan dan pelabuhan yang berada dalam wilayah Indonesia yang diperlakukan kebijakan melalui penghapusan atas rejim bea dan cukai berikut halangan nontarif serta pajak pada perdagangan internasional dalam hal kepabean diberlakukan sama sebagaimana produk sektor produksi lokal bilamana dijual di dalam negeri kebijakan ini berguna untuk mengurangi atau menghilangkan keseluruhan hambatan perdagangan di mana barang dapat mendarat, masuk, ditangani, diproduksi atau dilakukan penjualan ulang, dan direekspor tanpa intervensi kepabean hanya berlaku pada perdagangan internasional.

Batam pada tahun 1960-an sebagai basis logistik minyak bumi, tepatnya di Pulau Sambu. Pada dekade 1970-an, dengan tujuan awal menjadikan Batam sebagai Singapura-nya Indonesia, maka sesuai Keputusan Presiden nomor 41 tahun 1973, Pulau Batam ditetapkan sebagai lingkungan kerja daerah industri dengan didukung oleh Otorita Pengembangan Daerah Industri Pulau Batam atau lebih dikenal dengan Badan Otorita Batam (BOB) sebagai penggerak pembangunan Batam. Kini menjadi Badan Pengusahaan (BP Batam).Seiring pesatnya perkembangan Pulau Batam, pada dekade 1980an, berdasarkan Peraturan Pemerintah Nomor 34 tahun 1983, wilayah Kecamatan Batam yang merupakan bagian dari Kabupaten Kepulauan Riau, ditingkatkan statusnya menjadi Kotamadya Batam yang memiliki tugas dalam menjalankan administrasi pemerintahan dan kemasyarakatan serta mendudukung pembangunan yang dilakukan Otorita Batam (BP Batam).

Di era reformasi pada akhir dekade tahun 1990-an, dengan Undang-Undang nomor 53 tahun 1999, maka Kotamadya administratif Batam berubah statusnya menjadi daerah otonomi, yaitu Pemerintah Kota Batam untuk menjalankan fungsi pemerintahan dan pembangunan dengan mengikutsertakan Badan Otorita Batam (BP Batam). 


\section{Kawasan Ekonomi Khusus}

Meningkatkan penanaman modal melalui penyiapan kawasan yang memiliki keunggulan geoekonomi dan geostrategis; Optimalisasi kegiatan industri, ekspor, impor, dan kegiatan ekonomi lain yang memiliki nilai ekonomi tinggi; Mempercepat perkembangan daerah melalui pengembangan pusat-pusat pertumbuhan ekonomi baru untuk keseimbangan pembangunan antar wilayah; dan Mewujudkan model terobosan pengembangan kawasan untuk pertumbuhan ekonomi, antara lain industri, pariwisata dan perdagangan sehingga dapat menciptakan lapangan pekerjaan.

Kek terdiri dari satu dan atau beberapa zona yaitu pengolahan ekspor, pariwisata, logistik, teknologi informasi, industri, energi dan model ekonomi lainnya. KEK Sei Mangkei, KEK Tanjung Lesung, KEK Mandalika, KEK Palu, KEK Bitung, KEK Tanjung Api-Api, KEK Morotai, KEK Maloy Batuta Trans Kalimantan (MBTK), KEK Tanjung Kelayang, KEK Sorong, Kek arun lhoksumawe dan Kek galang batang

\section{Berapa lama waktu yang diperlukan} untuk menyelesaikan persetujuan KEK?

- Pemerintah kabupaten/kota melakukan verifikasi dan evaluasi terhadap dokumen usulan pembentukan KEK dalam jangka waktu paling lama 20 (dua puluh) hari kerja sejak diterimanya dokumen usulan secara lengkap untuk memberikan persetujuan atau penolakan.

- Dewan Nasional melakukan verifikasi dan evaluasi terhadap dokumen usulan pembentukan KEK dalam jangka waktu paling lama 45 (empat puluh lima) hari kerja sejak diterimanya dokumen usulan secara lengkap untuk memberikan persetujuan atau penolakan.

\section{Bagaimana Proses Penetapan KEK ?}

Dewan Nasional melakukan kajian terhadap usulan pembentukan KEK dalam jangka waktu paling lama 45 hari kerja sejak diterimanya dokumen usulan lengkap.

Dewan Nasional melakukan evaluasi kebenaran prosedur pengusulan dan kelengkapan dokumen yang disampaikan. Dalam hal usulan pembentukan KEK memenuhi prosedur dan lengkap dokumen yang disampaikan, Dewan Nasional melakukan Kajian.

Berdasarkan hasil kajian, Dewan Nasional memutuskan untuk menyetujui atau menolak usulan pembentukan KEK. Keputusan menyetujui dan menolak dilakukan dalam Sidang Dewan Nasional.

Dalam hal Dewan Nasional menyetujui pembentukan KEK, Dewan Nasional mengajukan rekomendasi pembentukan KEK kepada Presiden disertai dengan Rancangan Peraturan Pemerintah tentang penetapan suatu lokasi sebagai KEK. KEK yang telah ditetapkan harus siap beroperasi paling lambat 3 (tiga) tahun sejak tanggal ditetapkan.

Dalam hal Dewan Nasional menolak usulan pembentukan KEK, penolakan disampaikan secara tertulis kepada pengusul disertai alasan.

\section{Bagaimana proses persetujuan usulan KEK?}

Pembentukan KEK diusulkan kepada Dewan Nasional oleh:

- Badan Usaha;

- Pemerintah kabupaten/kota; atau

- Pemerintah provinsi.

- Kementerian / Lembaga Pemerintah Non Kementerian

- Untuk Badan Usaha, usulan disampaikan melalui provinsi setelah memperoleh persetujuan pemerintah kabupaten/kota.

- Untuk disampaikan melalui pemerintah provinsi.

- Untuk Pemerintahan Provinsi, usulan disampaikan setelah mendapat persetujuan pemerintah kabupaten/kota

4. Kriteria penetapan KEK?

Usulan lokasi KEK harus memenuhi kriteria:

- Sesuai dengan Rencana Tata Ruang Wilayah dan tidak berpotensi mengganggu kawasan lindung

- Adanya dukungan dari pemerintah provinsi dan/atau pemerintah kabupaten/kota yang bersangkutan;

- Terletak pada posisi yang dekat dengan jalur perdagangan, internasional atau dekat dengan jalur pelayaran internasional di Indonesia atau terletak pada wilayah potensi sumber daya unggulan

- Mempunyai batas yang jelas.

5. Dokumen apa saja yang harus 
disampaikan?

Dokumen yang harus disampaikan oleh Badan Usaha :

- Formulir Usulan

- Surat Kuasa Otoritas ( Jika Pengusul merupakan Konsorsium)

- Akta Pendirian Badan Usaha

- Profil Keuangan 3 (tiga) tahun terakhir yang sudah diaudit.

- Persetujuan dari pemerintah kabupaten/kota dengan lokasi KEK yang diusulkan

- Surat pernyataan mengenai nilai ekuitas paling sedikit $30 \%$ dari nilai investasi KEK yang diusulkan

- Deskripsi rencana pengembangan serta luas area KEK yang diusulkan

- Peta Detail lokasi pengembangan serta luas area KEK yang diusulkan

- Rencana peruntukan ruang pada lokasi KEK yang dilengkapi dengan peraturan zonasi

- Studi Kelayakan ekonomi dan finansial

- Analisis mengenai dampak lingkungan hidup sesuai dengan ketentuan peraturan perundang-undangan

- Usulan jangka waktu beroperasinya KEK dan rencana strategis pengembangan KEK

- Izin Lokasi

- Rekomendasi dari otoritas pengelola infrastruktur pendukung

- Pernyataan kesanggupan melaksanakan pembangunan dan pengelolaan KEK

Dokumen yang harus dipenuhi oleh Kabupaten/Kota :

- Formulir Usulan

- Deskripsi rencana pengembangan serta luas area KEK yang diusulkan

- Peta Detail lokasi pengembangan serta luas area KEK yang diusulkan

- Rencana peruntukan ruang pada lokasi KEK yang dilengkapi dengan peraturan zonasi

- Studi Kelayakan ekonomi dan finansial

- Analisis mengenai dampak lingkungan hidup sesuai dengan ketentuan peraturan perundang-undangan

- Usulan jangka waktu beroperasinya KEK dan rencana strategis pengembangan KEK

- Penetapan lokasi atau bukti hak atas tanah

- Rekomendasi dari otoritas pengelola infrastruktur pendukung

- Pernyataan kesanggupan melaksanakan pembangunan dan pengelolaan KEK

- Komitmen pemkab/kota terkait rencana pemberian insentif dan kemudahan

\section{METODE PENELITIAN}

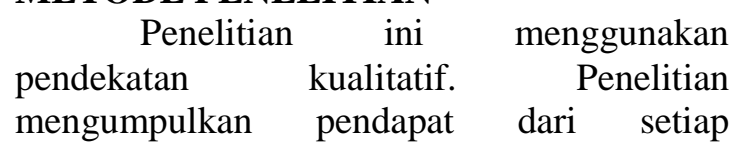
pemangku kepentingan yang didapatkan dari data sekunder yaitu media cetak dan online yang terpercaya. Peneliti juga melakukan studi literatur yang ada serta memperhatikan kesimpulan dari para peneliti yang terdahulu.

Peneliti membandingkan pendapatpendapat yang ada untuk kemudian ditarik sebuah kesimpulan yang akan menjadi tawaran solusi dalam permasalahan yang terjadi.

\section{HASIL PENELITIAN DAN PEMBAHASAN}

Silang pendapat mengenai transformasi FTZ menjadi KEK harusnya tidak menuai polemik seperti sekarang ini. Pemerintah dan pengusaha berdiri berhadaphadapan dalam menyelesaikan permasalahan ini. Masing-masing berdiri dengan keyakinan dengan sejumlah argumentasi dalam misi penyelamatan ekonomi batam.

Pemerintah datang membawa konsep ekonomi model baru yaitu KEK dengan dalil akan memberikan kemudahan dan insentif yang memadai untuk menarik investor menanamkan modalnya di kota ini. Sekaligus, konsep ini dianggap akan menyelesaikan polemik dualisme kepemimpinan Batam (Pemerintah Kota versus Badan Pengusahaan Batam).

Keunggulan geo ekonomi dan geostrategi wilayah serta diberikan fasilitas dan insentif khusus sebagai daya tarik investasi merupakan alasan pemerintah menerapkan KEK. KEK akan memberikan keunggulan pada fasilitas amortisasi yang dipercepat, keringanan pajak deviden, tax holiday dan tax allowence bagi perusahaan yang baru masuk dan nilai investasinya harus diatas $\mathrm{Rp} 500$ miliar. Pertanyaannya, bagaimana dengan nasib UMKM lokal dengan nilai dibawah 500 miliar? 
KEK yang diatur dalam UndangUndang 39 Tahun 2009, sedikitnya telah menetapkan dua belas (12) KEK yang tersebar dari barat hingga timur wilayah Indonesia didukung dengan penyelenggaraan infrastruktur, pemberian fasilitas dan insentif serta kemudahan berinvestasi. Diantaranya yang sudah ditetapkan yaitu KEK Sei Mangkei , Tanjung Lesung, Mandalika, Palu, Bitung, Tanjung Api-Api, Morotai, Maloy Batuta Trans Kalimantan (MBTK), Tanjung Kelayang, Sorong, Arun Lhoksumawe dan KEK Galang Batang. Masing-masing dengan kekhususannya yang dibagi dalam satu dan atau beberapa zona yaitu pengolahan ekspor, pariwisata, logistik, teknologi informasi, industri, energi dan model ekonomi lainnya.

$$
\text { KEK idealnya dimaksudkan }
$$

meningkatkan penanaman modal melalui penyiapan kawasan yang memiliki keunggulan geoekonomi dan geostrategis; Optimalisasi kegiatan industri, ekspor, impor, dan kegiatan ekonomi lain yang memiliki nilai ekonomi tinggi; Mempercepat perkembangan daerah melalui pengembangan pusat-pusat pertumbuhan ekonomi baru untuk keseimbangan pembangunan antar wilayah; dan Mewujudkan model terobosan pengembangan kawasan untuk pertumbuhan ekonomi, antara lain industri, pariwisata dan perdagangan sehingga dapat menciptakan lapangan pekerjaan.

Namun, di sisi lain, pengusaha bersikukuh berpandangan bahwa FTZ masih menjadi harapan dan model ekonomi yang cocok dengan kondisi desain awal kawasan ini dibentuk. Tidak adanya kepastian hukum akibat bongkar pasang sistem ekonomi batam, menjadi hal yang patut untuk diperhatikan. Bagaimana tesisnya? setiap investor dan pelaku usaha butuh kepastian dalam berusaha. Kemelut percakapan seperti ini tentu akan semakin mengurangi daya tawar Batam.

Pengusaha berdalih, apabila pemerintah ingin memperbaiki atau menambah insentif ekonomi di Batam demi memperbaiki kondisi kota ini, yang sejak semula di desain sebagai salah satu kawasan tulang punggung perekonomian kota batam. Lebih baik pemerintah tidak merubah sistem FTZ yang sudah ada dan sudah terlanjur dikenal sebagai image di mata investor, sembari memperlengkapi hal-hal yang di rasa perlu. Utamanya menyelesaikan persoalan tumpang tindih dualisme kepemimpinan di batam.

Pelaku usaha dan masyarakat sudah terlanjur menikmati fasilitas FTZ yang selama ini diterapkan. Bila pemerintah tetap memaksakan menerapkan KEK tanpa menghiraukan para pelaku usaha, maka daerah di luar KEK harus dikenakan PPN (Pajak Pertambahan Nilai) dan PPnBM (Pajak Penjualan atas Barang Mewah). Sebab, tidak semua daerah Batam akan dijadikan KEK. Beberapa wilayah Batam akan dilakukan zonasi dalam menetapkan kawasan KEK. Akibatnya tentu saja, semua barang-barang akan naik dan batam akan kehilangan keistimewaannya selama ini. Akibatnya para pelaku usaha dan masyarakat yang akan menanggung akibatnya.

Menurut penelitian Muzwardi (2016), menyimpulkan lalu lintas barang dan pelayaran internasional untuk menjadi pelabuhan bebas yang bisa memenuhi visi dan misi Kota Batam menjadi pengelola kawasan tujuan investasi terbaik di Asia Pasifik. permasalah infrastruktur, keterbatasan sumber daya manusia dan perijinan yang belum satu atap menjadi hambatan tersendiri untuk menjadikan Batam sebagai pelabuhan bertaraf internasional dan pelabuhan hub. Tujuan dari penelitian ini ialah untuk mengetahui pengelolaan Pelabuhan di Kota Batam dan pengembangan infrastruktur pelabuhan sebagai cara untuk meningkatkan sesuai standar internasional. Metode penelitian yang digunakan ialah metode kualitatif. Pada penelitian ini dapat disimpulkan bahwa kondisi manajemen pelabuhan kargo batam harus ditingkatkan terutama dalam perluasan dermaga dan efesiensi perijinan.

Sudah sepatutnya pemerintah dan pengusaha serta pemangku kepentingan terkait mau duduk bersama menbicarakan persoalan ini secara utuh dan komprehensif. Pemerintah pusat dalam hal sebagai pengambil keputusan (decision maker) harus menjadikan pertimbangan daerah menjadi masukan yang vital untuk didengarkan. Jangan sampai Pendekatan top down (Jakarta Centris) akan membuat Batam menjadi "kelinci percobaan", sehingga semakin memperkeruh iklim investasi. Memberikan dampak yang positif bagi perkembangan industri dan UMKM, serta menjamin iklim usaha dalam 
memberikan kepastian bagi para pelaku usaha adalah harapan kita semua.

Perdebatan ini harus tetap didasari demi menjawab permasalahan Batam dewasa ini. Masyarakat sebenarnya tidak terlalu memusingkan mengenai perdebatan yang elitis ini. Masyarakat hanya membutuhkan kepastian akan perbaikan mengenai ekonomi di kota ini. Tidak peduli apakah itu berbentuk FTZ dan KEK, yang paling penting bisa memperbaiki situasi kelesuan ekonomi batam ini.

Menarik apa yang dikatakan Bapak Reformasi Ekonomi China Deng Xiaoping yang telah berhasil mengangkat derajat Bangsa China mengimbangi hegemoni Amerika Serikat dewasa ini. Deng beranggapan, "Tidak masalah apakah kucing itu hitam atau putih, yang terpenting dia bisa menangkap tikus". Pepatah ini yang seharusnya yang menjadi kuncian kita semua.

\section{SIMPULAN}

Berdasarkan hasil penelitian dan pembahasan, maka dapat ditarik kesimpulan sebagai berikut:

1) Ada perbedaan persepsi antar para pemangku kepentingan tentang sistem yang terbaik dalam optimalisasi ekonomi Batam agar segera diselesaikan. Penting agar semua stakeholder terkait tentang permasalahan ini mau duduk bersama untuk menyelesaikan persoalan ekonomi yang ada di batam;

2) Pemerintah pusat harus menggunakan pendekatan dari bawah ke atas untuk menampung aspirasi dari para pemangku kepentingan yang paling sering bersentuhan dengan permasalahan yang ada.

\section{DAFTAR PUSTAKA}

https://bpbatam.go.id/ini/batamGuide/batam_ history.jsp, diakses 8 Agustus 2018

UU 39 Tahun 2009 tentang Kawasan Ekonomi Khusus

https://id.wikipedia.org/wiki/Kawasan_Perdag angan_Bebas_Indonesia, diakses 8 Agustus 2018

Undang-Undang Republik Indonesia Nomor 36 Tahun 2000 tentang Kawasan Perdagangan Bebas dan Pelabuhan Bebas. https://www.cnnindonesia.com/ekonomi/2018 0604085527-92-303165/pengusahatolak-batam-jadi-kawasan-ekonomikhusus, diakses 8 Agustus 2018

http://batam.tribunnews.com/2018/04/14/pem erintah-targetkan-5-kek-di-batamdarmin-mau-tetap-ftz-silakan-tapijangan-cemburu-ya, diakses 8 Agustus 2018 